Business and Economics Research Journal

Volume 7 Number 32016

pp. $73-88$

ISSN: $1309-2448$

DOI Number: 10.20409/berj.2016321809

\title{
Gelişmekte Olan Ülkelerde Yolsuzluk ve Demokrasi'nin DYY Üzerindeki Etkisi: Ampirik Bir İnceleme
}

\author{
Ahmet Ay \\ Oktay Kizılkaya ${ }^{\mathrm{b}}$ \\ Tuba Akar
}

\begin{abstract}
Öz: Bu çalışmada, 1995-2013 dönemi 10 gelişmekte olan ülke için yolsuzluk ve demokrasinin doğrudan yabancı yatııımlar üzerindeki etkisi ampirik olarak sınanmıştır. Çalışmada panel birim kök testleri, panel eşbütünleşme testi, panel FMOLS eşbütünleşme tahmincisi ve panel VEC nedensellik analiz yöntemleri kullanılmıştır. Çalışmada yolsuzluk, demokrasi ve doğrudan yabancı yatırımların uzun dönemde eşbütünleşik olduğu bulgusuna ulaşılmıștır. Eşbütünleşme katsayılarının tahmin sonuçları değerlendirildiğinde paneli oluşturan 10 geliş̧mekte olan ülke için yolsuzluk düzeyinin azalması ve demokrasi düzeyinin artması doğrudan yabancı yatırımları pozitif yönde etkilemektedir. Nedensellik analizine göre ise kısa dönemde yolsuzluktan doğrudan yabancı sermaye yatırımlarına doğru tek yönlü, uzun dönemde ise yolsuzluk ve demokrasiden doğrudan yabancı sermaye yatırımlarına doğru tek yönlü bir nedensellik ilişkisi olduğu sonucuna ulaşılmıştır. Bu bulgular demokrasi ve yolsuzlukların doğrudan yabancı sermaye yatııımları üzerinde anlamlı bir etkisi olduğunu yönündeki hipotezleri desteklemektedir. Yabancı yatırımcıların günümüzde ev sahibi ülkedeki politik rejimin güvenilirliğini test ettiği görülmektedir. Ev sahibi ülkelerin, yabancı yatııımıya yönelik politikalarını gözden geçirmesi önemli bir faktör olarak ortaya çıkmaktadır.
\end{abstract}

Anahtar Sözcükler: Yolsuzluk, Demokrasi, Doğrudan Yabancı Yatırımlar, Gelişmekte olan Ülkeler, Panel Veri Analizi

JEL Sinıflandırması: D73, C33, D72, F23

\section{The Effects of Corruption and Democracy on FDI in Developing Countries: An Empirical Investigation}

Abstract: In this paper, the effects of corruption and democracy on foreign direct investments are examined empirically for 10 developing countries over the period 1995-2013. Panel unit root tests, panel cointegration test, panel FMOLS estimator, and panel vector error correction causality methods are employed in the paper. According to the findings, there is a cointegration relationship among corruption, democracy, and foreign direct investments. Decrease of corruption and increase of democracy level, affect foreign direct investments positively in 10 developing countries which constitute panel, in accordance with evaluating estimate results of cointegration coefficients. According to the findings obtained from the causality analysis, there is unidirectional causality from corruption to foreign direct investments in the short run while there is unidirectional causality from corruption and democracy to foreign direct investments in the long run. These findings support the hypothesis which argue that democracy and corruption have significant effects on foreign direct investments. Today, it can be seen that foreign investors test the trustworthiness of political regime in host country. Reviewing policies towards foreign investors appears as a substantial factor for host countries.

Keywords: Corruption, Democracy, Foreign Direct Investments, Developing Countries, Panel Data Analysis

JEL Classification: D73, C33, D72, F23

${ }^{a}$ Prof. Dr., Selçuk University Faculty of Economics and Administrative Sciences, Department of Economics, Konya, Turkiye, ahmetay@selcuk.edu.tr

${ }^{\mathrm{b}}$ Assist. Prof. Dr., Ahi Evran University, Faculty of Economics and Administrative Sciences, Department of Economics, Kırşehir, Turkiye, kizilkayaoktay@yahoo.com

'Res. Assist., Karamanoğlu Mehmetbey University, Faculty of Economics and Administrative Sciences, Department of Economics, Karaman, Turkiye, akartubaa@gmail.com 


\section{Giriş}

Dünya ekonomisinde meydana gelen küreselleşme sürecinin etkisiyle birlikte uluslararası sermaye hareketlerinin önündeki engeller kalkmaya başlamıştır. Bunun sonucunda ticari serbestlikte yaşanan artışla beraber ülkeler arasında mal, hizmet, bilgi ve sermaye hareketleri hız kazanmıştır. Hızlanan bu sermaye hareketleriyle birlikte gelişmiş teknoloji, güçlü sermaye yapısı ve nitelikli işgücüne sahip çok uluslu şirketler ön plana çıkmıştır. Dünya genelinde farklı bölgelerde bu şirketlere daha kolay ticaret ve yatırım yapma imkânı sağlanmıştır. Öte yandan bu şirketlerin kendi ülkelerinde çevreye duyarlı bir üretim anlayışı benimseme zorunluluğu bulunmaktadır. Bu nedenle yerine getirmek zorunda oldukları standartlar ek maliyet unsuru oluşturmaktadır. Çok uluslu şirketler bu maliyetlerden kaçınmak için üretim sonucu ortaya çıkan bu kirliliğin azaltılmasında ya da giderilmesi konusunda daha az kontrolün olduğu gelişmekte olan ülkelere yatırım yapmaya yönelmişlerdir ${ }^{1}$. Dünya ekonomisinde yaşanan bu gelişmelerle beraber ev sahibi ülke konumunda olan gelişmekte olan ülkelerin hedeflerinden birisi de bu şirketleri kendi ülkesine yatırım yapmaya ikna edebilme çabası olmuştur. Çünkü doğrudan yabancı yatırımların (DYY) ev sahibi ülkeye yeni teknolojiler getirmek, istihdam sağlamak ve ekonomik büyümeyi sürdürülebilir kılmak gibi olumlu etkileri bulunmaktadır.

Çok uluslu şirketler yatırım yapacakları ülkeleri seçerken ev sahibi ülkedeki bir takım faktörleri göz önünde bulundurmaktadırlar. Ekonomik faktörler olarak; ev sahibi ülkenin ekonomik büyüme oranı, kamu harcamaları, geçmiş yıllardaki DYY akımları, kişi başına düşen GSYiH gibi makroekonomik değişkenler DYY üzerinde etkili olabilmektedir. Ancak bu ekonomik faktörlerin yanında hükümetlerin sergilemiş oldukları yönetim şekli de DYY konusunda istikrarlı bir yatırım ortamı oluşturmak için etkili olabilmektedir. Bu nedenle yatırımcılar DYY riskini miminize edebilen, güvence altına alınmış fikri mülkiyet haklarına sahip olan, düşük yolsuzluk seviyesi gözlemlenen ve daha az sosyal çatışmaların olduğu ülkeleri tercih etmektedir (Biglaiser ve DeRouen, 2006: 52). Bir ülkedeki riskin ve belirsizliğin ne düzeyde olacağı o ülkedeki demokratik ortama ve politik istikrara bağlıdır. Bu nedenle DYY'ın belirleyicilerini sadece ekonomik düzeyde değerlendirmemek gerekmektedir. Yolsuzluk da bu ülkelerde riske ve belirsizliğe neden olan önemli bir faktör olarak karşımıza çıkmaktadır. Yolsuzluk, serbest piyasa ekonomisinin işlerliği için gerekli olan ortamın, toplumsal normların, değerlerin olmadığı sosyal bir bozukluk ve ülkelerin uluslararası ekonomik ilişkilerinin gelişmesi önünde katlanılmaz bir engel olmaktadır (Primorac ve Smoljic, 2011: 178).

Bu çalışmada, teorik bilgiler ve literatürdeki diğer çalışmalar dikkate alınarak demokrasi ve yolsuzluğun DYY üzerindeki etkisi analiz edilmek istenmiştir. Çalışma dört bölümden oluşmaktadır. Giriş bölümünden sonraki ikinci bölümde yolsuzluk, demokrasi ve DYY arasındaki ilişki teorik düzeyde ele alınmıştır. Üçüncü bölüm literatüre ayrılmış ve bu konuyla ilgili daha önce yapılan uygulamalı çalışmalar ile sonuçlarına yer verilmiştir. Dördüncü bölüm olan çalışmanın ampirik bölümünde ise 10 gelişmekte olan ülke kapsamında, veri aralığı 1995-2013 dönemi olmak üzere panel veri yöntemi kullanılmıştır. Elde edilen bulgular sonuç kısmında ele alınarak politika önerilerinde bulunulmuştur.

\section{Teorik Çerçeve}

Yolsuzluğun tanımı konusunda ortak bir görüş olmasa da genel olarak "yolsuzluk, özel çıkarlar için kamu gücünün kötüye kullanılması" şeklinde ifade edilmektedir. Diğer bir tanım ise, yolsuzluğu "kamu görevlilerinin özel çıkarları (veya aile ve ilgili grupların çıkarları) için görev tanımlarında belirtilen yetki ve sorumluluklarından saptıkları bir davranış" şeklinde ifade etmektedir. Bu davranış rüşveti (kamu otoritelerinin kararlarını etkilemek amacı ile para veya başka faydalar sağlama), yakınlara iltimas, kişisel faydalar için görevi kötüye kullanma gibi durumları (kamu mal ve hizmetlerini vb. yasal olmayan şekilde kullanma) içermektedir. Böylece yolsuzluk toplumun tümünü etkilemesinin ötesinde işletmelerin faaliyetlerini ve ekonomik kalkınmayı engellemektedir. Yolsuzluk piyasa ekonomisi işleyişinde bir düzensizliğe neden olmakta, karar verme süreçlerini bozmakta ve bu yüzden de rasyonelliği ve ekonomik verimliliği etkilemektedir (Caetano ve Caleiro, 2009:46, Primorac ve Smoljic, 2011: 177).

1990'ların başında dünya küreselleşme olgusu ile beraber ekonomistler yolsuzluğun ekonomi üzerindeki olumsuz etkisini açıklamayı amaçlamışlardır. Hines (1995), yolsuzluğun ekonomik büyümeyi 
negatif etkilediğini, Rose-Ackerman (1999), yolsuzluğun üretim maliyetlerini artırdığını, Della Porta ve Vanucci (1999), ev sahibi ülkedeki yolsuzluğun DYY'yi olumsuz etkilediğini, Busse-Hefeker (2007) yolsuzluğun DYY girişlerinin önemli bir belirleyicisi olduğunu, Mathur ve Singh (2013) ise yolsuzluğun yatırımcıların yatırım kararlarını büyük oranda etkilediğini savunmuştur. Yolsuzluk hakkında olumsuz (negatif) ve olumlu (pozitif) olmak üzere iki farklı etki literatürde tartışılmaktadır. Olumsuz etki; "yolsuzluk, maliyetleri ve belirsizliği arttırdığı için doğrudan yabancı yatırımlar üzerinde azaltıcı bir etkiye sahiptir" şeklinde ifade edilmektedir. Olumlu etki ise; "ülkelerdeki gelişmemiş düzenleme ve denetlemeler bürokrasiyi azaltırken üretim maliyetlerini de azaltmaktadır ve bu durum doğrudan yabancı yatırımları arttırmaktadır" şeklinde ifade edilmektedir. Literatürdeki bu iki farklı görüş birbirlerine tamamen zıt argümanlar olarak sunulmuştur. Bu belirgin teorik çelişkiyi çözmenin tek yolu bu iki görüşün farklı durumlarda ortaya çıktığının ve faaliyet gösterdiğinin kabul edilmesidir. Yolsuzluk, özellikle yerleşmiş piyasa kuruluşlarının olduğu ülke ekonomilerinde engelleyici rol oynarken, piyasa kuruluşlarının düzgün işlemediği kurumsallaşmamış ülke ekonomilerinde geliştirici rol oynamaktadır (Cuervo-Cazurra, 2008:13).

Yolsuzluğun ekonomik maliyetinin hesaplanması zor olmasına rağmen firmalar üzerine özellikle rüşvetten kaynaklanan ek maliyetler yükleyebilmektedir. Bu sebeple yolsuzluk ve rüşvete karşı istikrarlı ve etkin bir yasal çerçevenin varlığı yabancı yatırımlar için cazibe unsurunu temsil etmektedir (Caetano ve Caleiro, 2009: 45). Yolsuzluk düzeyinin DYY akımları üzerindeki olumsuz etkileri konusundaki tartışmalar genellikle iş yapma maliyeti bağlamında analiz edilmiştir. Çünkü yabancı yatırımcılar yatırımlarını yönetebilmek için gereken devlet izinlerini ve lisanslarını almak için rüşvet şeklinde ek maliyetler ödemek zorunda kalabilmekte ve yolsuzluklar yatırım maliyetini artırabilmektedir. Böylesi ek maliyetler yatırımın karlığını azaltırken yolsuzluğun genel olarak kar üzerinde bir vergi olarak düşünülmesine sebep olmaktadır (Al-Sadig, 2009:269).

Öte yandan, modern ve demokratik toplumlar giderek artan bir şekilde yolsuzluğun sistematik aksaklığına vurgu yapmaktadırlar. Bu sadece ahlaki olarak yanlış düşünülmemekte aynı zamanda ülkelerin siyasi ve ekonomik sistemlerindeki bozuklukların bir parçası olarak görülmektedir (Primorac ve Smoljic, 2011: 177). Yolsuzluğun ekonomik performansı olumsuz yönde etkilediği, yatırımlar ve ekonomik büyüme üzerinde negatif etkileri bulunduğu, sağlık hizmetleri ve eğitim hizmetlerinde altyapının kalitesini ve kamu yatırımlarının verimliliğini bozduğu ve gelir dağılımında adaletsizliğe neden olduğu düşünceleri tartışılmaktadır. Ayrıca yolsuzluk ekonomilerde belirsizliği de arttırmaktadır. Tüm bu örnekler aynı zamanda DYY'nin önemli belirleyicileri olmuştur. Bu yüzden yabancı yatırımcıların yolsuzluk düzeyi yüksek olan ülkelerden kaçınmak eğiliminde olmaları beklenen bir durumdur (Al-Sadig, 2009:269).

Yolsuzluk, siyasi rejimleri ne olursa olsun, gelişmiş, gelişmekte olan veya az gelişmiş bütün ülkelerde görülmektedir. Demokrasilerde dahi, çok yüksek seviyede olmasa bile yolsuzluk görülebilmektedir. Ancak daha demokratik olan, hukukun üstünlüğüne daha çok bağlı olan gelişmiş ülkelerde, az gelişmiş ülkelere nazaran yolsuzluğun daha düşük olduğu, otoriter rejimler ve diktatörlük ile yönetilen ülkelerde yolsuzluk için daha elverişli bir ortamın olduğu söylenebilir (Öner, 2005:44). Bir ülkedeki demokratik kurumların varlığı çok uluslu şirketler için devletin politik güvenilirliğini sağlamaktadır. Yabancı yatırımcılar sadece özel mülkiyetleri konusunda güvenirlilik değil, aynı zamanda ev sahibi ülke hükümetinin siyasi rejiminin güvenilirliği konusuyla da ilgilenmektedirler. Bu yüzden ev sahibi ülkenin vergi üzerindeki politikaları, döviz kuru ve sermaye kontrolü vb. firma faaliyetlerini ve yatırım kararlarını etkilemektedir. Bu kapsamda ev sahibi ülke hükümetleri, yabancı yatırımcıya zarar veren politikalarını değiştirmek ve gözden geçirmek için girişimlerde bulunmaya başlamışlardır (Li, 2006: 64). Bununla birlikte istikrarlı bir politik ortam yabancı yatırımcıların karar verme süreçlerinde etkin olarak rol oynamaya başlamıştır. İstikrarlı bir politik ortam ise demokrasi tarafından sağlanmakta ve bunu başarabilen ülkelerde ise yatırım daha cazip hale gelebilmektedir.

Dunning (1958), Vernon (1966), Caves (1971), Hymer (1976), Buckley and Casson (1976), Dunning (1977, 1988), Rugman (1980) ve Hennart (1989) tarafından geliştirilen ve OLI modeli olarak bilinen teori DYY'nin belirleyicilerini açıklamaya çalışmaktadır (Oxelheim vd. , 2001:384). Model çok uluslu şirketlerin yabancı pazarlarda değer yaratan faaliyetlerini açıklamaya çalışan bir modeldir (Yeşil, 2010:49). Firmaların uluslararası faaliyetlere belli durumlar altında karar verdiklerini öne sürmektedir. Teori çok uluslu şirketlerin 
yabancı pazarlarda değer yaratan faaliyetlerinin yapı ve niteliklerini bazı şartların tatmin edilmesine bağlamıştır. Bu şartlar, OLI' yi oluşturan unsurlar (O, L ve I) olarak üç tür avantajlar grubuna işaret etmektedir (Smarzynska, 2002:41). Buna göre O (ownership) yönetim becerisi, yenilik kapasitesi, önemli süreçlere sahip olmak, tanınmış markalara sahip olmak gibi üstünlükleri, işletmenin yalnız kendisinde bulunan üretim ayrıcalıklarını açıklamaktadır. I (internalization) içselleştirme üstünlüklerini, diğer bir deyişle, şirketin bir piyasaya neden başka yollarla değil de doğrudan yatırım şeklinde gireceğini açıklamaktadır. L (location) ise konumla ilgili üstünlükleri yani yatırımın yapılacağı piyasayla ilgili üstünlükleri açıklamaktadır. Buna örnek olarak yabancı pazarlardaki vergi avantajları, sağlam altyapı, uluslararası ulaşım ve iletişim maliyetleri ile üretim faktör kalitelerindeki farklııklar gösterilebilir. Öte yandan yatırım yapılacak ülkenin konumu (L) yatırımın karlılığını artıracak özellikte olması gerekir. Bunun için makro ekonomik koşulların uygun olması gerekmektedir. Örneğin; ekonomik ve siyasi istikrarın sağlanmış olması, dengeli bir kur, faiz ve fiyat politikası izlenmesi gerekmektedir. Ayrıca yatırım yapılacak ülkenin konumu, ticari kısıtlamaların üstesinden gelme ve ev sahibi ülke politikalarından dolayı ortaya çıkan bölgesel avantajlar ile ilişkilendirilmektedir (Smarzynska, 2002:41; Yeşil, 2010:49). Yolsuzluk ve demokrasi gibi faktörler ise son yıllardaki gelişmelerle beraber ülkede yatırım yapmak isteyen yabancı yatırımcıların kararını etkileyen unsurlar olarak kabul edilmektedir. Çünkü yolsuzluk ve demokrasi ev sahibi ülkede riski ve belirsizliği etkileyen faktörler olarak kabul edilmektedir. Söz konusu model kapsamında yolsuzluk ve demokrasinin ülkedeki yatırımın karlılı̆ını etkileme potansiyelinin yüksek olmasından dolayı ülkenin konumuyla ilgili faktörler arasında sayılması önem arz etmektedir. Bu kapsamda gelişmekte olan ülkelerde "riski ve belirsizliği etkileyen yolsuzluk ve demokrasinin DYY üzerindeki etkisi ne yöndedir?" sorusu önemli görülmektedir. Çalışma ilgili soruya cevap aramaktadır. Bu soru çerçevesinde çalışmada yolsuzluk ve demokrasinin DYY üzerindeki etkisi temsili 10 gelişmekte olan ülke için panel eşbütünleşme ve panel nedensellik analizleri kullanılarak araştırılacaktır.

Çalışmanın literatüre katkısı iki yöndedir: i) Dünyadaki son gelişmelerle beraber yolsuzluk DYY'nin en önemli belirleyicileri arasında kabul edilmektedir. Bu bağlamda birinci hipotez; düşük yolsuzluk düzeyinin DYY için önemli bir faktör olduğudur. ii) Çok uluslu şirketler gittikleri ülkede yatırımlarının siyasi rejim tarafından güvence altına alınmalarını istemektedirler. Bu bağlamda ikinci hipotez; ev sahibi ülkede demokrasi düzeyi yükselmesi DYY'i artırmaktadır. Bu çalışma ilgili hipotezleri sınayarak literatüre katkı yapmayı amaçlamaktadır.

\section{Ampirik Literatür}

Yolsuzluk, DYY ve demokrasi üzerine yapılan çalışmalar incelendiğinde çalışmaların büyük bir kısmında yolsuzluk ve DYY arasında negatif, demokratik yapı ve DYY girişleri arasında ise pozitif bir ilişkinin olduğu tespit edilmiştir. Öte yandan yolsuzluğun DYY girişlerini pozitif etkilediği sonucuna ulaşan çalışmalar da mevcuttur. Bunun yanı sıra DYY akımlarının da yolsuzluğa neden olduğunu ileri süren çalışmalar literatürde yer almaktadır. Ayrıca bazı çalışmalar daha otoriter rejimlerde daha fazla bir DYY girişi sağlandığı sonucuna ulaşılırken bir kısım çalışma ise demokratik yapının DYY girişlerini etkilemediği sonucuna ulaşmıştır. Bu durum, literatürde bazı yatırımcıların daha hesap verilebilir ve daha şeffaf bir demokratik ülkeye yatırım yapmak istemedikleri varsayımıyla açıklanabilmektedir.

İlk olarak, literatürde yolsuzluk ile DYY arasında negatif bir ilişki olduğuna dair sonuçlar bulan çalışmalar ele alındığı takdirde örneğin; Smarzynska ve Wei (2000), yolsuzluk ve DYY'nin niteliği konusunda yapılmış olan analiz Doğu Avrupa ve Eski Sovyet Sosyalist Cumhuriyetler Birliği üzerinedir. Çalışma sonucunda yolsuzluğun DYY girişlerini azalttığını ve DYY yapısının iş ortaklığı şeklinde olduğu tespit edilmiştir. Habib ve Zurawicki (2001), 111 ülke üzerine yaptıkları çalışmada yolsuzluğun yatırımlar üzerinde negatif etkisi olduğunu bulmuşlardır. Ayrıca yolsuzluğun yerel yatırımlar üzerine olan etkisinin yabancı yatırımlara göre daha zayıf olduğunu sonucu elde edilmiştir. Ketkar vd. (2005), gelişmiş ve gelişmekte olan 54 ülkede yolsuzluk ve DYY arasında anlamlı bir ilişki olduğu tespitinde bulunmuşlardır. Araştırma sonucunda yolsuzluk düzeyinin yüksek olduğu ülkelere daha az sermaye girişi olduğu sonucu elde edilmiştir. Egger ve Vinner (2006), yolsuzluk ve DYY arasındaki ilişkiyi analiz etmek için 21 OECD ve 59 OECD üyesi olmayan ülkeler arasında 1983-1999 yıllarını kapsayan bir çift yönlü panel veri analizi yapmışlardır. Analiz 
sonucunda yolsuzluğun DYY üzerinde negatif bir etkiye neden olduğunu bulmuşlardır. Caetano ve Caleiro (2009), "bulanık mantık" metodunu kullanarak 97 ülke için yolsuzluk ve DYY arasındaki ilişki için bir analiz yapmışlardır. Bu çalışmada ülkeler iki kümeye ayrılmıştır, birinci kümedeki ülkeler yolsuzluğun yüksek olduğu diğeri ise düşük olduğu ülkelerdir. Araştırmanın sonucunda yolsuzluğun yüksek olduğu ülkelerde yolsuzluğun DYY üzerinde negatif bir etkisi bulunurken, yolsuzluğun düşük olduğu ülkelerde bu etkinin oldukça az olduğu görülmüştür. Al-Sadig (2009), 117 ülke için yaptığı çalışmada 1984-2004 yıllarını ele almış, DYY ve yolsuzluk arasındaki ilişkiyi Panel Veri Analizi ile ölçerek yolsuzluk düzeyinin DYY üzerinde olumsuz etkileri olduğu sonucuna ulaşmıştır. Koyuncu (2011), 2000-2007 yılları arasındaki 71 ülkeye ait yıllık verileri kullanarak bir ülkedeki kurumsal kaliteyi gösteren göstergelerden yargı bağımsızlığının, mülkiyet hakkının ve yolsuzluğun doğrudan ve dolaylı yabancı sermaye girişleri üzerinde etkisi olup olmadığını panel regresyon modelleri yardımıyla analiz etmiştir. Analiz sonuçlarına göre; mülkiyet hakkının korunmasının ve yolsuzlukların azaltılmasının doğrudan yabancı sermaye üzerinde olumlu etkisi olduğu tespit edilmiştir. Samadi vd. (2011), D8 ülkeleri (Bangladeş, Mısır, Endonezya, İran, Malezya, Nijerya, Pakistan ve Türkiye) için yaptıkları çalışmada yolsuzluk ve DYY arasındaki ilişkiyi 1996-2009 yıllarını ele alarak incelemişlerdir. Panel Veri Analizi sonucunda yolsuzluğun hem finansal gelişmeyi hem de DYY'i negatif etkilediği sonucuna ulaşılmıştır ve yolsuzluğun finansal piyasaları olumsuz yönde etkilediği söylenmiştir. Castro ve Nunes (2013), 73 ülke üzerine yaptıkları çalışmada yolsuzluğun düşük olduğu ülkelerde DYY girişlerinin daha büyük olduğunu bulmuşlardır. Tosun vd. (2014) Türkiye üzerine yaptıkları çalışmada yolsuzluğun hem kısa hem uzun dönemde DYY girişleri üzerinde bozucu etkileri olduğunu bulmuşlardır.

Öte yandan yolsuzluğun DYY girişlerini pozitif etkilediği sonucuna ulaşan çalışmalar da literatürde mevcuttur. Yolsuzluğun DYY girişlerini pozitif etkilediğini ortaya koyan çalışmalardan biri Egger ve Winner (2005)'e aittir. 73 adet gelişmiş ve gelişmekte olan ülke üzerine yapılan çalışmada yolsuzluğun DYY girişleri için bir uyarıcı olduğu ve uzun dönemde yolsuzluğun DYY girişlerini artırdığı sonucu elde edilmiştir. CuervoCazurra (2006), yapmış olduğu çalışmada yolsuzluk ile DYY arasındaki ilişkiyi analiz etmiş ve analiz sonucunda yolsuzluğun yatırımcıları farklı düzeylerde etkileyeceği sonucu çıkmıştır. Çalışmada ulaşılan sonuç, "kendi ülkesinde rüşvete karşı yasaları olan ülkeler yüksek yolsuzluk bulunan ülkelere yatırım yapmaktan kaçınırken, kendi ülkesinde yüksek düzeyde yolsuzluk bulunan yatırımcılar yüksek yolsuzluğun olduğu ülkelere yatırım yapmaktan kaçınmamaktadırlar" şeklinde özetlenmiştir. Brouthers vd. (2008), yolsuzluk piyasa çekiciliğinin DYY'nin farklı türleri üzerine yaptığı etkileri analiz etmişlerdir. Yapılan analiz sonucunda yolsuzluğun kaynak arayan DYY üzerinde caydırıcı etkisi bulunurken, piyasa arayışında olan DYY üzerinde eğer yolsuzluktan kaynaklanan ek maliyetlere katlanılabilinir ise yolsuzluğun benimsenebileceği sonucuna varılmıştır. Cuervo-Cazurra (2008), yapmış olduğu çalışmada geçiş ekonomileri için yolsuzluk ve DYY arasındaki ilişkiyi analiz etmiştir. Çalışma yolsuzluğun DYY'i negatif yönde etkilediğini ancak geçiş ekonomilerinde yüksek yolsuzluk düzeyinin daha fazla DYY çektiğini ifade etmiştir. Craigwell ve Wright (2011), 42 gelişmekte olan ülke üzerine yaptığı çalışmada yolsuzluk ve DYY girişleri arasında çift yönlü bir nedenselliğe ulaşırken, DYY girişlerinden yolsuzluğa doğrusal olmayan bir ilişki tespit etmişlerdir.

Demokrasi ve DYY arasındaki ilişkiyi ele alan bazı çalışmalarda daha otoriter rejimlerde daha fazla bir DYY girişi sağlandığı sonucuna ulaşııırken bir kısım çalışmada ise demokratik yapının DYY girişlerini etkilemediği sonucuna ulaşılmıştır. Busse (2003), demokrasi ve DYY arasındaki ilişkiyi ölçmek için 69 gelişmekte olan ülke için 1972-1999 yılları için Panel Veri ve Kesit Analizi yapmışlardır. Analiz sonucunda yatıımların daha çok demokratik ülkelere yapıldığı sonucu elde edilmiştir. Li ve Resnick (2003), 53 gelişmekte olan ülke için 1982-1995 dönemi için yaptıkları çalışmada demokratik kurumların DYY üzerinde etkilerinin ne yönde olduğunu araştırmışlardır. Araştırmanın sonucunda demokrasinin DYY üzerinde olumlu ve olumsuz etkilerinin olabileceği sonucuna ulaşılmıştır. DYY'nin GSYiH'ın yüzdesi olarak ele alındığı durumlarda demokrasinin DYY'i olumlu etkileyeceği sonucuna ulaşmışlardır. Demokratik kurumların fikri mülkiyet haklarını koruyarak DYY üzerinde olumlu etkide bulunacağına işaret etmektedir. Jensen (2003), 114 ülke üzerine yaptığı panel regresyon ve kesitsel analiz ile demokrasi ve DYY arasındaki ilişkiyi analiz etmiştir. Analiz sonucunda demokrasi ve DYY arasında nedensel bir ilişki bulunmuştur. Demokratik ülkelerin daha fazla DYY çektikleri, dolayısıyla demokratik kurumların DYY'i büyük oranda pozitif yönde etkilediği savunulmaktadır. Demokratik yönetişimin ülke güvenilirliğini etkilediği ve bu durumun da yatırımcıların yatırım kararını etkilediği ileri sürülmüştür. Jakobsen ve Soysa (2006), Li ve Resnick (2003)'ten yola çıkarak 
örneklem ile veri sayısı artırılarak ve ayrıca çalışmaya Çin de dahil edilerek demokrasi ve DYY arasındaki ilişkiyi analiz etmişlerdir. Araştırma 1984-2001 dönemini kapsarken, zaman serileri ve kesitsel analiz kullanılmıştır. Jakobsen ve Soysa (2006), Çin'in daha otoriter rejimdeyken daha güçlü fikri mülkiyet haklarına sahip olduğunu, bunun da DYY girişlerini artırdığı sonucuna ulaşmışlardır. Guerin ve Manzocchi (2009), yaptıkları çalışmada gelişmiş ülkelerden gelişmekte olan ülkelere yapılan DYY yatırımlar üzerinde siyasal rejimin ne türde bir etki yaptığını analiz etmişlerdir. Çalışma 1992-2004 dönemini kapsarken, çalışma sonucunda demokrasinin DYY miktarını ve olasılığını pozitif yönde etkilediği sonucuna ulaşılmıştır. Arslan ve Ökten (2010), demokrasi ve DYY arasındaki ilişkiyi Türkiye açısından analiz etmişlerdir. Çalışmada 1970-2010 dönemi ele alınmış ve Johansen Eşbütünleşme Analizi ve Hata Düzeltme Modeli kullanılmıştır ve değişkenler arasında uzun dönem ilişkisi olduğu sonucuna varılmıştır. Asiedu ve Lien (2011) çalışmalarında demokrasi, DYY ve doğal kaynaklar arasındaki ilişkiyi incelemiş 90 ülkede demokraside artışın DYY girişlerini artırdığını, 22 ülkede ise bu artışın DYY girişlerini azalttığı sonucunu elde etmişlerdir. Ayrıca demokrasinin DYY üzerindeki etkisinin ev sahibi ülkedeki doğal kaynakların payına bağlı olduğunu tespit etmişlerdir.

Demokrasi ile DYY arasında negatif bir ilişkinin varlığını ileri süren çalışmaların mevcut olduğu daha önce ifade edilmişti. Resnick (2001), Asya, Latin Amerika ve Karayipler için DYY ile demokrasi arasındaki ilişkiyi analiz etmiştir. Zaman serisi ve kesitsel analizin kullanıldığı çalışmada demokrasinin DYY üzerinde negatif etkisi olduğu sonucuna varılmıştır. Yang (2007), demokrasi ve DYY arasındaki ilişkiyi 134 ülke üzerinde analiz etmiştir. Çalışmada 1983-2002 yılları temel alınmış ve çalışma sonucunda rejim tipleri gözetilmemesine rağmen demokrasi ile DYY düzeyi ve GSYiH içindeki payı arasında anlamlı bir ilişki bulunmamıştır. Çalışmanın sonucunda demokrasinin daha fazla DYY çekmede bir rolünün olmadığı sonucuna ulaşılmıştır. Okafor vd. (2011), demokrasi ve DYY girişleri arasındaki ilişkiyi Sahraaltı (SubSaharan) Afrika ülkeleri için analiz etmişlerdir. Analize 48 Afrika ülkesi dahil edilmiş ve 1996-2008 yılları baz alınmıştır. En küçük kareler yönteminin kullanıldığı çalışma sonuçlarına göre daha etkin, daha hesap verilebilir ve daha şeffaf bir demokratik ülkeye daha az DYY girişi olduğu sonucuna ulaşıımıştır. Dolayısıyla çalışma sonucu demokrasi ile DYY arasında negatif bir ilişki olduğunu söyleyen literatürdeki diğer çalışmaları destekler niteliktedir.

Son olarak yolsuzluk, demokrasi ve DYY arasındaki ilişkiyi ele alan çalışmalar ise şu şekilde sıralanabilir. Gani (2007), Asya ve Latin Amerika üzerine yaptığı çalışmada hukukun üstünlüğü, yolsuzluğun kontrolü, hükümet etkinliği ve politik istikrarın DYY girişlerini pozitif etkilediği sonucuna ulaşmışlardır. Busse-Hefeker (2007) 83 ülke üzerinde yaptıkları çalışma da hükümet istikrarı, içsel ve dışsal çatışmalar, hukuk ve düzen, bürokratik kalitenin DYY'i daha az etkilerken, yolsuzluğun ve demokratik sorumluluğun DYY girişlerinin önemli bir belirleyicisi olduğunu bulmuşlardır. Haksoon (2010) yaptığı çalışmada yüksek politik haklara sahip ülkelerde daha yüksek DYY çıkışları olduğunu, yolsuzluğun yüksek olduğu ve demokrasi düzeyinin düşük olduğu ülkelerde ise daha yüksek DYY girişi olduğu sonucuna ulaşmışlardır. Mathur ve Singh (2013), yaptıkları çalışmada DYY, demokrasi ve yolsuzluk ilişkisini analiz etmişlerdir. Analize 29 ülke dahil edilmiştir ve çalışma 1980-2000 dönemini kapsamaktadır. Analiz sonucunda yolsuzluğun yatırımcıların yatırım kararlarını büyük oranda etkilediği sonucuna ulaşıırken daha demokratik ülkelerin daha az sermaye girişine sahip olduğu sonucu elde edilmiştir.

\section{Ekonometrik Analiz}

\section{1. Model ve Veri Seti}

Yolsuzluk ve demokrasinin doğrudan yabancı sermaye yatırımları (DYY) üzerindeki etkisinin ampirik olarak sınmayı amaçlayan bu çalışmada aşağıdaki gibi panel veri formatında bir doğrusal regresyon modeli kurulmuştur.

$\operatorname{lnFDI} I_{i t}=\alpha_{0 i}+\alpha_{1 i} C R_{i t}+\alpha_{2 i} D_{E M O}+u_{i t} \quad i=1, \ldots, N ; t=1, \ldots T$

Bu modelde InFDI doğrudan yabancı sermaye yatırımlarının doğal logaritmasını (\$), COR yolsuzluğu (endeks) ve DEMO (endeks) demokrasi düzeyini temsil etmektedir. Analizde kullanılan veri seti 1995-2013 
dönemi yıllık verilerinden oluşmakta olup, 10 gelişmekte olan ülkeyi kapsamaktadır. Bu ülkeler Brezilya, Çin, Filipinler, Hindistan, Kolombiya, Malezya, Meksika, Singapur, Şili ve Türkiye'dir. Bu ülkeler yükselen piyasa ekonomileri olarak da ifade edilen, dünya GSYiH içinde önemli bir payı olan ve en fazla DYY yatırımları çeken ülkeler arasındadır. Bu nedenle çalışmada örneklem olarak özellikle seçilmiştir. Doğrudan yabancı sermaye yatırımları Dünya Bankası, yolsuzluk verileri Transparency International, demokrasi verileri Freedom House veri tabanlarından elde edilmiştir. Demokrasi endeksi 1-7 arasında olup 1 en yüksek, 7 en düşük demokrasi düzeyini temsil etmektedir. Dolayısıyla endeksteki artış (azalış) demokrasi düzeyinin azalmasını (artmasını) ifade etmektedir. Yolsuzluk endeksi ise 0-10 arasında olup, 10 yolsuzluk olmadığını, 0 ise bozukluğu temsil etmektedir. Bu nedenle endeksteki artış (azalış) yolsuzluğun azaldığını (arttığını) belirtmektedir. Bu çalışmada kullanılacak değişkenlere ait tanımlayıcı istatistikler ve korelasyon matrisi Tablo 1'de verilmekte ve değişkenlere ait seriler grafiksel olarak Grafik 1'de gösterilmektedir.

Tablo 1'deki tanımlayıcı istatistiklere göre COR ortalaması medyan değeri InFDI ve DEMO'nun değerlerinden daha yüksektir. Ayrıca InFDI, COR ve DEMO değişkenleri arasında pozitif korelasyon olduğu görülmektedir.

Tablo 1. Tanımlayıcı İstatistikler (1995-2013)

\begin{tabular}{llll}
\hline & InFDI & COR & DEMO \\
\hline Tanımlayıcı İstatistikler & & & \\
\hline Ortalama & 4,333 & 4,445 & 3,506 \\
Medyan & 3,160 & 3,610 & 3,250 \\
Maksimum & 26,059 & 9,400 & 7,000 \\
Minimum & 0,052 & 2,160 & 1,000 \\
Std. Hata & 4,681 & 2,004 & 1,440 \\
Gözlem Sayısı & 190 & 190 & 190 \\
\hline Korelasyon Matrisi & & & \\
\hline InFDI & 1 & 1 & 1 \\
COR & 0,814 & $-0,008$ & \\
DEMO & 0,164 & & \\
\hline
\end{tabular}

Grafik 1'de ise analizde kullanılan serilerin eğilimleri gösterilmektedir. Buna göre InFDI, COR ve DEMO değişkenleri arasında olası bir beraber hareket gözlemlenebilmektedir. Ancak bu çalışmada daha güvenilir sonuçlar elde etmek için panel birim kök, panel eşbütünleşme, panel FMOLS ve panel nedensellik gibi daha gelişmiş ekonometrik yöntemler kullanılacaktır. 


\section{Grafik 1: Çalışmada Kullanılan Değişkenlere Ait Seriler}

LNFD I

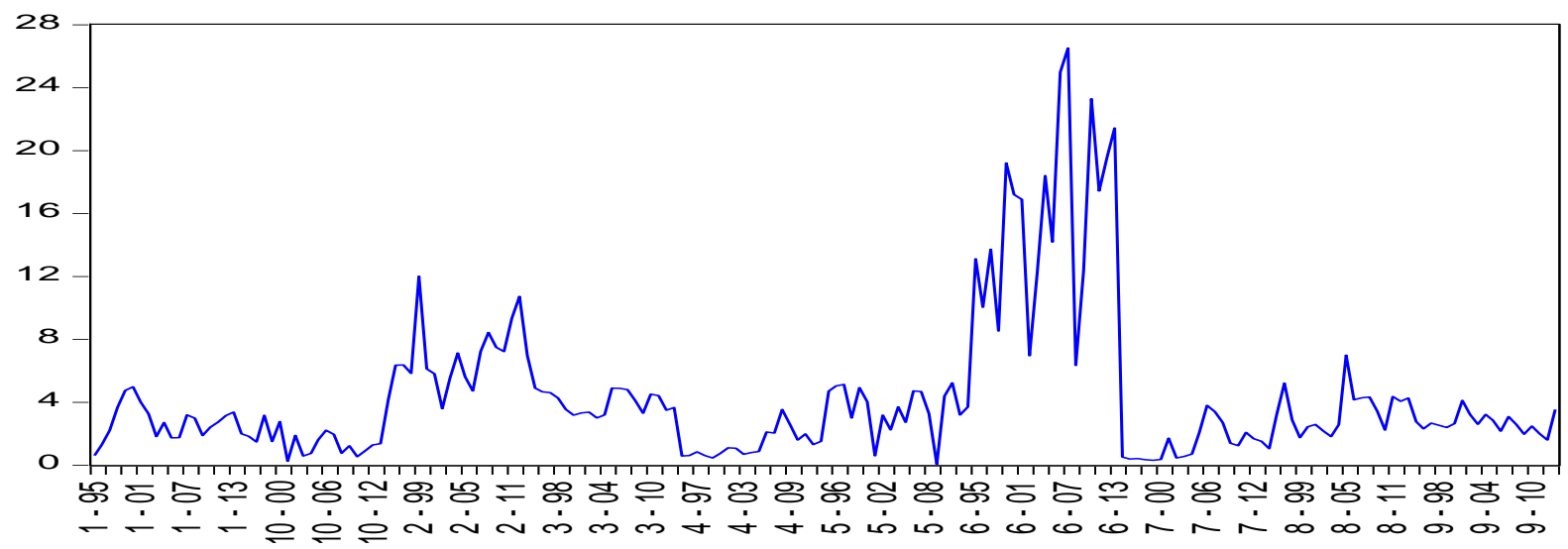

COR

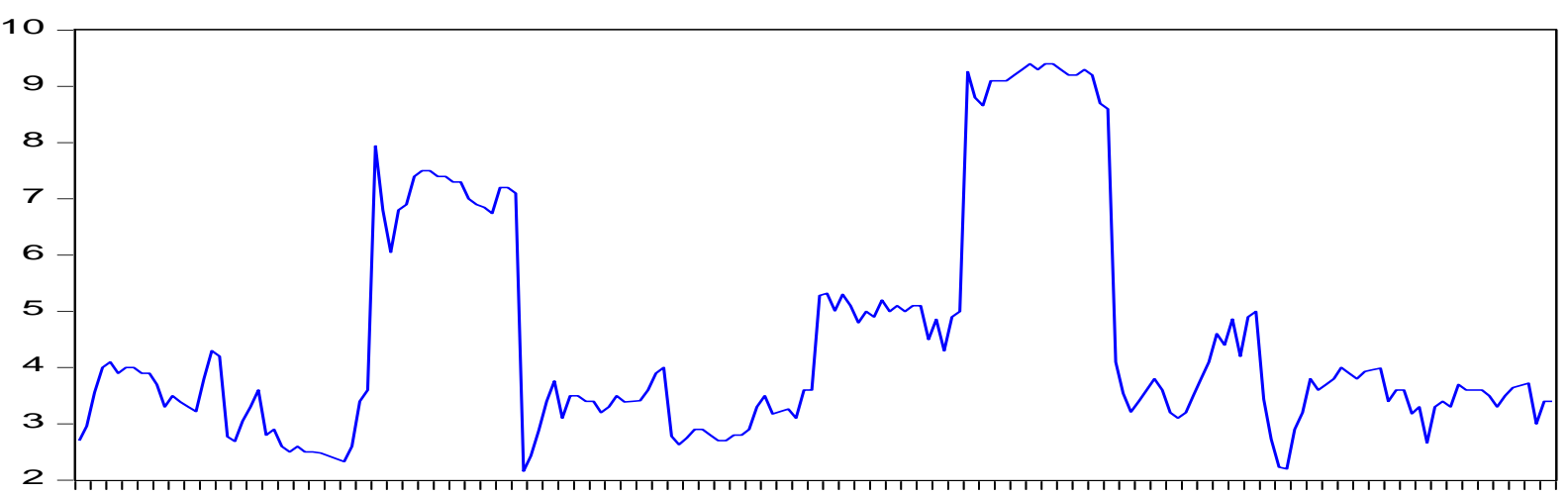

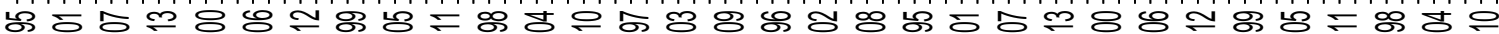

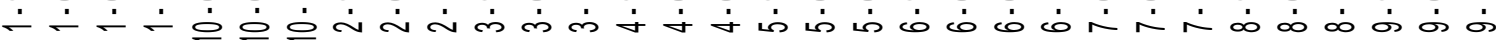

DEM

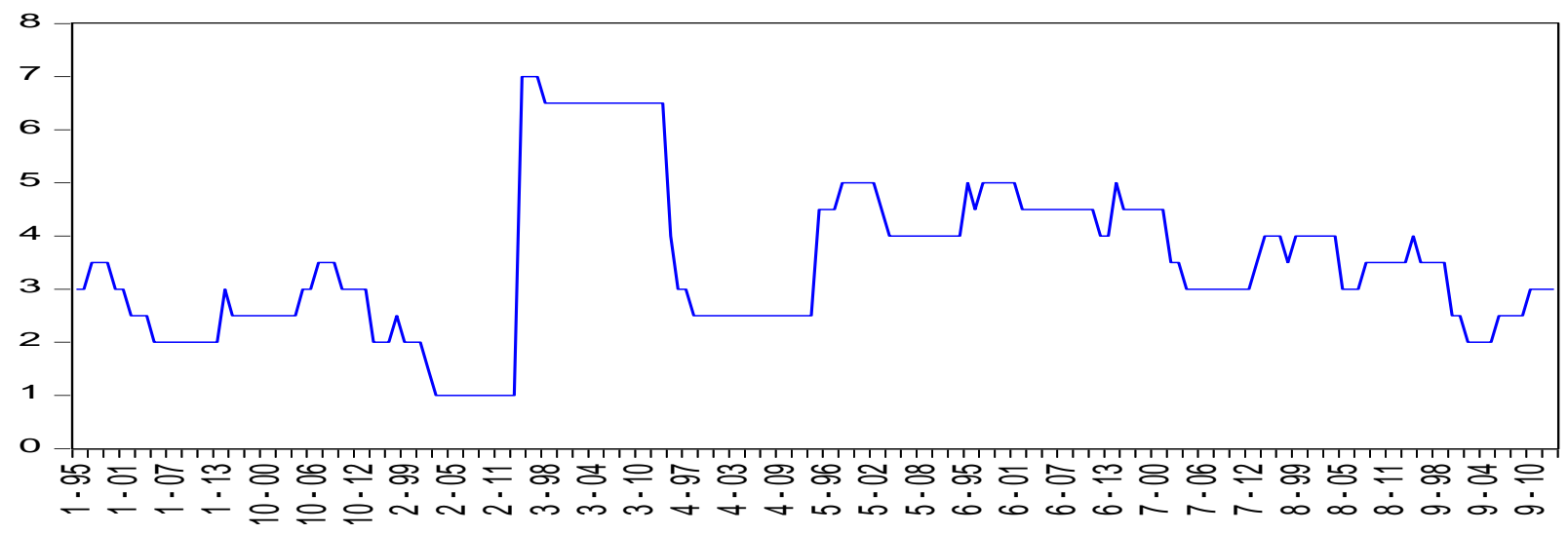

\section{2. Yöntem (Metodoloji)}

Bu çalışmada yolsuzluk ve demokrasinin DYY üzerindeki etkisi dört adımda sınanacaktır. Birinci adımda, Maddala ve Wu (1999, ADF-Fisher), Levin vd. (2002, LLC) ve Im vd. (2003, IPS) tarafından geliştirilen panel birim kök testleri ile araştırılacaktır. Ikinci adımda Pedroni $(1999 ; 2004)$ tarafından geliştirilen panel eşbütünleşme testi ile uzun dönemli ilişki araştırılacaktır. Üçüncü adımda Pedroni (2000) 
tarafından geliştirilen panel FMOLS ve panel DOLS yöntemleri ile eşbütünleşme katsayıları tahmin edilecektir. Dördüncü adımda değişkenler arasındaki nedensellik ilişkisi vektör hata düzeltme modeline dayalı panel nedensellik (panel VEC) analiz yöntemi ile araştırılacaktır.

Ampirik analize geçmeden önce değişkenlerin durağanlığının sınanması gerekmektedir. Eğer değişkenlere ait veriler durağansa, değişkenler arasındaki ilişkileri tespit etmek için regresyon analizi kullanılacak, durağan değilse sahte regresyon sorunu ortaya çıkacaktır. Bu durumda ise değişkenler arasında eşbütünleşme ilişkisinin olup olmadığı test edilecektir. Değişkenler arasında eşbütünleşme ilişkisi elde edildikten sonra tahmin edilecek katsayılar daha güvenilir sonuç vermektedir. Bu çalışmada durağanlık analizi için ilk olarak Levin vd. (2002, LLC) testi kullanılacaktır.

LLC panel birim kök testi için şu modelin tahmin edilmesini gerektirmektedir:

$\Delta y_{i t}=\mu_{i}+\rho y_{i t-1}+\sum_{j=1}^{m} \alpha_{j} \Delta y_{i t-j}+\delta_{i t}+\theta_{t}+\varepsilon_{i t}$

Burada; $\Delta$ birinci fark operatörü, m gecikme uzunluğu, $\mu$ i ve $\theta$ t sırasıyla birime özgü sabit ve zaman etkileridir. Tüm i'ler için $\rho=0$ sıfır hipotezi, tüm i'ler için $\rho<0$ hipotezine karşı test edilmektedir. Sıfır hipotezinin reddedilmesi, serinin durağan olduğu anlamına gelmektedir.

Maddala ve Wu (1999) tarafından geliştirilen Fisher-ADF testi ise, her yatay kesit i için birim kök testlerinden elde edilen $\rho$ değerlerini birleştirir. Test parametrik değildir ve $2 \mathrm{n}$ serbestlik derecesiyle ki-kare dağılımına sahiptir. Testte $\mathrm{n}$ ise, paneldeki yatay kesit verisi sayısıdır. Bu test istatistiği şu şekildedir:

$\lambda=-2 \sum_{\mathrm{i}=1}^{\mathrm{n}} \log _{\mathrm{e}}\left(\mathrm{p}_{\mathrm{i}}\right) \sim \chi 2_{2 \mathrm{n} \text { (d.f. })}$

Burada; $\rho$ i birim i için ADF birim kök testinden elde edilen $p$ değeridir. ADF-Fisher testi, bireysel ADF regresyonlarındaki farklı gecikme uzunluklarına bağlı olmama avantajına sahiptir.

Im vd. (2003) tarafından geliştirilen IPS testi, LLC testini geliştirerek, paneldeki her bir kesit için $\mathrm{t}$ istatistiklerini hesaplayarak, ortalamasını almaktadır. Bu test, paneli oluşturan birimlerin her biri için $\rho$ değerlerinin değişkenlik göstermesine izin vermektedir. (3) numaralı eşitlik tekrar yazılırsa:

$\Delta y_{i t}=\mu_{i}+\rho y_{i t-1}+\sum_{j=1}^{m} \alpha_{j} \Delta y_{i t-j}+\delta_{i t}+\theta_{t}+\varepsilon_{i t}$

Sıfır hipotezi, tüm i'ler için $\rho=0$ ’a karşı en az bir i için $\rho<0$ hipotezine karşı test edilmektedir. Sıfır hipotezinin reddedilmesi, serinin durağan olduğu anlamına gelmektedir.

Literatürde durağan olmayan değişkenler arasında uzun dönemde eşbütünleşme ilişkisini sınamak için Pedroni (1999; 2004) tarafından geliştirilen panel eşbütünleşme testi sıklıkla kullanılmaktadır. Pedroni 'eşbütünleşme ilişkisi yoktur' şeklinde tanımlanan sıfır hipotezini test etmek için 7 farklı test istatistiği geliştirmiştir. Pedroni, bu istatistikleri panel eşbütünleşme regresyonundan elde edilen artıklardan elde etmektedir. Bu testlerin dördü grup içi (panel-v, panel- $\rho$, yarı parametrik panel-t ve parametrik panel-t) istatistiklerden, diğer üçü ise gruplar arası (grup- $\rho$ istatistiği, yarı parametrik group-t istatistiği ve parametrik group-t) istatistiklerden oluşmaktadır (Pedroni, 1999:660). Bu yedi istatistik kritik değerler ile karşılaştırılarak sıfır hipotezi reddedilmekte ya da kabul edilmektedir. Pedroni test istatistiklerinin kritik değerlerden büyük olması durumunda sıfır hipotezi reddedilmekte ve analize dâhil edilen değişkenler arasında uzun dönem eşbütünleşme ilişkisinin bulunduğuna karar verilmektedir.

Panel eşbütünleşme ilişkisi tahmin edildikten sonraki üçüncü adım uzun dönem eşbütünleşme katsayılarını tahmin etmektir. Bunun için Pedroni (2000) tarafından geliştirilen panel Fully Modified Ordinary Least Squares (FMOLS) yöntemi kullanılacaktır. FMOLS tahmincisi, aralarında uzun dönemli ilişki bulunan serilerin en küçük kareler yöntemiyle tahmin edilmesi durumunda sapmalı sonuçların ortaya 
çıkması üzerine geliştirilmiştir. FMOLS yöntemi, oto korelasyon ile içsellik problemini parametrik olmayan bir yaklaşım ile düzeltmektedir².

Dördüncü ve son adımda değişkenler arasındaki nedensellik ilişkisi araştırılacaktır. Bu kapsamda değişkenler arasındaki ilişkinin yönünü tespit edebilmek için hata düzeltme modeli (VEC) kullanılmıştır. Bu model hem kısa hem de uzun dönem nedensellik hakkında bilgi vermektedir. Bu çerçevede bir panel VEC modeli şöyle yazılmaktadır:

$\Delta \mathrm{y}_{\text {it }}=\alpha_{1 \mathrm{i}}+\sum_{\mathrm{k}=1}^{\mathrm{q}} \beta_{11 \mathrm{ik}} \Delta \mathrm{y}_{\mathrm{it}-\mathrm{k}}+\sum_{\mathrm{k}=1}^{\mathrm{q}} \beta_{12 \mathrm{ik}} \Delta \mathrm{x}_{\mathrm{it}-\mathrm{k}}+\lambda_{1 \mathrm{i}} \widehat{\varepsilon}_{\mathrm{it}-1}+\mathrm{v}_{1 \mathrm{it}}$
$\Delta \mathrm{x}_{\mathrm{it}}=\alpha_{2 \mathrm{i}}+\sum_{\mathrm{k}=1}^{\mathrm{q}} \beta_{21 \mathrm{ik}} \Delta \mathrm{x}_{\mathrm{it}-\mathrm{k}}+\sum_{\mathrm{k}=1}^{\mathrm{q}} \beta_{22 \mathrm{ik}} \Delta \mathrm{y}_{\mathrm{it}-\mathrm{k}}+\lambda_{2 \mathrm{i}} \hat{\varepsilon}_{\mathrm{it}-1}+\mathrm{v}_{2 \mathrm{it}}$

5 ve 6 nolu denklemlerde $\Delta$ birinci farkı, q gecikme uzunluğunu, $\lambda$ hata düzeltme terimini temsil etmektedir. Değişkenler arasındaki kısa dönem nedensellik ilişkisi Wald istatistiği ile test edilmektedir. Uzun dönemli nedensellik ilişkisi ise hata düzeltme teriminin katsayısının istatistiki olarak anlamlılığı araştırılarak test edilmektedir.

\section{3. Bulgular}

Yolsuzluk ve demokrasinin doğrudan yabancı sermaye yatırımları (DYY) üzerindeki etkisinin ampirik olarak sınmayı amaçlayan bu çalışmada Maddala ve Wu (1999, ADF-Fisher), Levin vd. (2002, LLC) ve Im vd. (2003, IPS) tarafından geliştirilen panel birim kök test sonuçları Tablo 2' de gösterilmektedir.

Tablo 2'deki sonuçlar değerlendirildiğinde değişkenlerin düzey değerlerinin durağanlığı konusunda karar verilememekte ancak ilk farklarında \%1 anlamlılık düzeyinde durağan olduğu görülmektedir. Bu durumda değişkenler arasında uzun dönemde bir eşbütünleşme ilişkinin varlığı test edilmelidir. Eğer değişkenler arasında eşbütünleşme varsa bu durumda elde edilen regresyon yanıltıcı olmayacaktır.

Tablo 2. Panel Birim Kök Test Sonuçları

\begin{tabular}{llll}
\hline Değişkenler & LLC & IPS & ADF-Fisher \\
\hline InFDI & $-1,589^{* *}$ & $-1,201$ & 17,333 \\
COR & $-0,135$ & $-2,021^{* *}$ & 8,427 \\
DEMO & $-2,344^{*}$ & 0,118 & 21,014 \\
$\Delta$ InFDI & $-10,271^{*}$ & $-8,606^{*}$ & $92,537^{*}$ \\
$\Delta$ COR & $-6,362^{*}$ & $-7,249^{*}$ & $84,265^{*}$ \\
$\Delta$ DEMO & $-7,566^{*}$ & $-6,366^{*}$ & $63,278^{*}$ \\
\hline
\end{tabular}

Açıklamalar: *, \%1 anlamlılık düzeyini, **, \%5 anlamlılık düzeyini, ***, \%10 anlamlılık düzeyini göstermektedir.

Tablo 3'de panel eşbütünleşme test sonuçları gösterilmektedir. Sabitli model değerlendirildiğinde, yedi istatistiğin dördü \%1 anlamlılık düzeyinde ve biri \%10 anlamlılık düzeyinde sıfır hipotezini reddettiği görülmektedir. Sabitli ve trendli modelde ise, yedi istatistiğin dördü \%1 anlamlılık düzeyinde sıfır hipotezinin reddedildiğini göstermektedir. Bu sonuçlar değişkenlerin uzun dönemde eş bütünleşik olduğunu desteklemektedir. 
A. Ay-O. Kizilkaya-T. Akar

Tablo 3. Panel Eşbütünleşme Test Sonuçları

\begin{tabular}{lcc}
\hline Test İstatistikleri & Sabitli & Sabitli ve Trendli \\
\hline Panel v & $-1,386$ & $-3,139$ \\
Panel rho & $-1,483^{* * *}$ & 0,944 \\
Panel PP & $-7,220^{*}$ & $-14,010^{*}$ \\
Panel ADF & $-6,796^{*}$ & $-7,806^{*}$ \\
Grup rho & $-0,717$ & 0,995 \\
Grup PP & $-7,178^{*}$ & $-10,642^{*}$ \\
Grup ADF & $-4,228^{*}$ & $-4,618^{*}$ \\
\hline Açılamalar: * \%1 anlamlllk düzeyini göstermektedir. & &
\end{tabular}

Panel eşbütünleşme ilişkisi tahmin edildikten sonra üçüncü adım uzun dönem eşbütünleşme katsayılarını tahmin etmektir. Bunun için Pedroni (2000) tarafından geliştirilen panel FMOLS tahmin yöntemi kullanılmıştır. Tablo 4'de panel FMOLS sonuçları hem paneli oluşturan her bir ülke için (country specific) hem de panel için gösterilmektedir.

Tablo 4. Panel Eşbütünleşme Katsayı Tahminleri

\begin{tabular}{|c|c|c|c|c|}
\hline & Panel & & & \\
\hline Ülkeler & COR & $\mathrm{t}$ ist. & DEMO & $\mathrm{t}$ ist. \\
\hline Brezilya & $1,68^{\mathrm{a}}$ & 3,04 & $0,67^{c}$ & 1,92 \\
\hline Çin Halk Cumh. & $-1,09^{c}$ & $-1,71$ & 0,28 & 0,16 \\
\hline Filipinler & $1,17^{\mathrm{a}}$ & 2,76 & 0,11 & 0,24 \\
\hline Hindistan & $2,28^{a}$ & 3,40 & $2,39^{c}$ & 1,81 \\
\hline Kolombiya & $-0,05$ & $-0,18$ & $-1,67^{\mathrm{a}}$ & $-3,75$ \\
\hline Malezya & $1,63^{\mathrm{c}}$ & 1,77 & $-0,96^{c}$ & $-1,88$ \\
\hline Meksika & $0,30^{c}$ & 1,89 & $-0,47^{c}$ & $-1,76$ \\
\hline Singapur & $5,90^{c}$ & 1,75 & $-4,44^{c}$ & $-1,69$ \\
\hline Şili & $-1,18$ & $-1,39$ & 0,28 & 0,16 \\
\hline Türkiye & $0,49^{c}$ & 1,70 & $-0,52^{c}$ & $-1,95$ \\
\hline Panel & $1,11^{a}$ & 3,59 & $-0,39^{b}$ & $-2,11$ \\
\hline
\end{tabular}

Açıklamalar: a,b,c; sırasıyla \%1, \%5, \%10 anlamlıık düzeyini göstermektedir. 
Tablo 4'deki sonuçlar değerlendirildiğinde, 1995-2013 döneminde 10 gelişmekte olan ülkeden oluşan panel için FMOLS sonuçlarına göre, yolsuzluk endeksindeki (COR) \%1'lik bir artış-endeksin artması yolsuzluğun azalmasını ifade etmekte- doğrudan yabanı sermaye yatııılarını (InFDI) \%1,11 oranında arttırmaktadır. Demokrasi endeksindeki (DEMO) \%1'likbir artış -endeksin artması demokrasi düzeyinin azaldığını ifade etmekte- doğrudan yabancı sermaye yatırımlarını (InFDI) \%0,39 oranında azaltmaktadır. Diğer bir ifadeyle panel FMOLS sonuçlarına göre bir ülkede demokrasi düzeyinin artması ve yolsuzluk düzeyinin azalması o ülkeye giren doğrudan yabancı sermaye yatırımlarında bir artış sağlamaktadır.

Paneli oluşturan ülkeler için bireysel sonuçlar yolsuzluk için değerlendirildiğinde Brezilya, Filipinler, Hindistan, Malezya, Meksika, Singapur ve Türkiye'de yolsuzluk düzeyinin azalması doğrudan yabancı sermaye yatırımlarında bir artış sağlamaktadır. Çin'de ise yolsuzluk düzeyinin artması doğrudan yabancı sermaye yatırımlarını arttırmaktadır. Kolombiya ve Şili için yolsuzluğun katsayısı istatistiki olarak anlamsızdır.

Bireysel sonuçlar demokrasi için değerlendirildiğinde Kolombiya, Malezya, Meksika, Singapur ve Türkiye'de demokrasi düzeyinin artması (demokrasi endeksinin azalması) doğrudan yabancı sermaye yatırımlarında artış sağlamaktadır. Brezilya ve Hindistan'da ise demokrasi düzeyinin artması doğrudan yabancı sermaye yatırımlarında azalış sağlamaktadır. Çin, Filipinler ve Şili'de ise demokrasi ile doğrudan yabancı sermaye yatırımları arasında istatistiki bir ilişki olmadığı görülmektedir.

Tablo 5. Panel Vektör Hata Düzeltmeye Dayalı Granger Nedensellik Test Sonuçları

\begin{tabular}{|c|c|c|c|c|}
\hline \multicolumn{4}{|c|}{ Kısa Dönem Nedensellik } & \multirow{2}{*}{$\begin{array}{c}\begin{array}{c}\text { Uzun Dönem } \\
\text { Nedensellik }\end{array} \\
\text { ECT(-1) }\end{array}$} \\
\hline & $\Delta \mathrm{InFDI}$ & $\Delta \mathrm{COR}$ & $\triangle \mathrm{DEMO}$ & \\
\hline \multirow[t]{2}{*}{$\Delta \operatorname{lnFDI}$} & & $4,965^{* *}$ & 1,015 & $-1,235$ \\
\hline & & $(0,025)$ & $(0,314)$ & {$[-12,11]^{*}$} \\
\hline \multirow[t]{2}{*}{$\triangle \mathrm{COR}$} & 0,081 & & 0,022 & 0,001 \\
\hline & $(0,774)$ & & $(0,866)$ & {$[0,04]$} \\
\hline \multirow[t]{2}{*}{$\triangle \mathrm{DEMO}$} & 0,449 & 0,729 & & $-0,016$ \\
\hline & $(0,507)$ & $(0,393)$ & & {$[-1.39]$} \\
\hline
\end{tabular}

Açıklamalar: *, \%1 ve ** \%5 anlamlııı düzeyini göstermektedir.

Tablo 5 'de ise değişkenler arasındaki ilişkinin yönünü belirlemek için uygulanan panel VEC nedensellik analiz sonuçları gösterilmektedir. Nedensellik sonuçlarına göre, kısa dönemde sadece yolsuzluktan doğrudan yabancı sermaye yatırımlarına doğru bir nedensellik ilişkisi olduğu görülmektedir. Uzun dönemde ise yolsuzluk ve demokrasiden doğrudan yabancı sermaye yatırımlarına doğru tek yönlü bir nedensellik ilişkisi olduğu görülmektedir. Bu ilişki eşbütünleşme ilişkisinin sonuçlarını desteklemektedir. Diğer bir ifadeyle demokrasi ve yolsuzluk düzeyindeki değişmeler doğrudan yabancı sermaye yatırımlarındaki değişmeleri etkilemektedir.

\section{Sonuç}

Bu çalışmada yolsuzluk ve demokrasinin doğrudan yabancı sermaye yatırımlar (DYY) üzerindeki etkisi 1995-2013 dönemi 10 gelişmekte olan ülke için ampirik olarak sınanmıştır. Çalışmada yöntem olarak panel birim kök testleri, panel eşbütünleşme testi, panel FMOLS tahmincisi ve panel VEC nedensellik analiz yöntemleri kullanılmıştır. Çalışmada yolsuzluk, demokrasi ve DYY'nin uzun dönemde eşbütünleşik olduğu bulgusuna ulaşılmıştır. Eşbütünleşme katsayılarının tahmin sonuçları değerlendirildiğinde yolsuzluk 
düzeyinin azalması (artması) DYY'nı arttırmaktadır (azaltmaktadır). Demokrasi düzeyinin artması (azalması) ise DYY'nı arttırmaktadır (azaltmaktadır). Başka bir ifadeyle, paneli oluşturan 10 gelişmekte olan ülke için yolsuzluk düzeyinin azalması ve demokrasi düzeyinin artması DYY'nı pozitif yönde etkilemektedir. Nedensellik analiz sonuçlarına göre ise kısa dönemde yolsuzluktan doğrudan yabancı sermaye yatırımlarına doğru, uzun dönemde ise yolsuzluk ve demokrasiden doğrudan yabancı sermaye yatırımlarına doğru tek yönlü bir nedensellik ilişkisi olduğu sonucuna ulaşılmıştır. Bu bulgular demokrasi ve yolsuzluk seviyelerinin doğrudan yabancı sermaye yatırımları etkilediğini göstermektedir.

Çalışmamızda paneli oluşturan ülkeler için bireysel sonuçlar yolsuzluk için değerlendirildiğinde, Brezilya, Filipinler, Hindistan, Malezya, Meksika, Singapur ve Türkiye'de yolsuzluk düzeyinin azalması doğrudan yabancı sermaye yatırımlarında bir artış sağlamaktadır. Smarzynska ve Wei (2000), Habib ve Zurawicki (2001), Ketkar vd. (2005), Egger ve Vinner (2006), Al-Sadig (2009), Koyuncu (2011), Samadi vd. (2011) ve Castro ve Nunes (2013) gibi çalışmalar bu sonucu desteklemektedir. Çin'de ise yolsuzluk düzeyinin artması doğrudan yabancı sermaye yatırımlarını arttırmaktadır. Bu sonuç literatürdeki Egger ve Winner (2005), Cuervo-Cazurra (2006), Brouthers vd. (2008), Cuervo-Cazurra (2008) gibi çalışmalarda ifade edildiği gibi yolsuzlukların yatırımların ek maliyetlerini ortadan kaldırabilmesi özelliği ile açıklanabilmektedir. Öte yandan, paneldeki bireysel sonuçlar demokrasi için değerlendirildiğinde, Kolombiya, Malezya, Meksika, Singapur ve Türkiye'de demokrasi düzeyinin artması (demokrasi endeksinin azalması) doğrudan yabancı sermaye yatırımlarında artış sağlamaktadır. Bu bulgulara literatürdeki Busse (2003), Li ve Resnick (2003), Jensen (2003), Jakobsen ve Soysa (2006), Guerin ve Manzocchi (2009), Arslan ve Ökten (2010) ve Asiedu ve Lien (2011) gibi çalışmalarda da rastlanılmaktadır. Bu çalışma ile birlikte literatürdeki diğer çalışmalar değerlendirildiğinde yatırımların daha çok demokratik ülkelere yapıldığı, demokratik kurumların fikri mülkiyet haklarını koruyarak DYY üzerinde olumlu etkide bulunduğu, demokratik yönetimlerin ülke güvenilirliğini etkilediği ve bu durumun da yatırımcıların yatırım kararını etkilediği ileri sürülebilmektedir. Ayrıca uygulama sonuçları, Brezilya ve Hindistan'da demokrasi düzeyinin artması doğrudan yabancı sermaye yatırımlarında bir azalışa sebep olduğunu göstermektedir. Çin, Filipinler ve Şili'de ise demokrasi ile doğrudan yabancı sermaye yatırımları arasında istatistiki bir ilişki olmadığı görülmektedir. Bu sonuçlar da daha önce literatür kısmında belirtilen bazı çalışmaların bulgularıyla desteklenmektedir.

DYY'nin ev sahibi ülkeye yeni teknolojiler getirmek, istihdam sağlamak ve ekonomik büyümeyi sürdürülebilir kılmak gibi olumlu etkilerini göz önüne aldığımızda, uygulama sonuçları ülke ekonomilerinin artık DYY çekme yolunda ekonomik faktörler dışında sosyal ya da siyasal olarak ifade edilebilen yolsuzluk ve demokrasi gibi faktörlerin üzerine de eğilmeleri gerektiğini göstermektedir. Yabancı firmalar ev sahibi ülkede yatırım riskini miminize etmek, fikri mülkiyet haklarını güvence altına almak, ek maliyetlere katlanmamak gibi amaçlara ulaşmak için daha az sosyal çatışmaların olduğu, yolsuzluk ve rüşvete karşı istikrarlı ve etkin bir mücadelenin olduğu ülkeler aramaktadırlar. Ayrıca bir ülkedeki riskin ve belirsizliğin ne düzeyde olacağı o ülkedeki siyasi rejimlere bağlı olabilmektedir. Ev sahibi ülkedeki hükümetler yabancı yatırımcıya yönelik politikalarını yolsuzluk ve demokrasi ölçeğinde gözden geçirmelidir. Nihayet bu konudaki literatür genel olarak değerlendirildiğinde yatırımların daha çok, yolsuzluk düzeyinin az olduğu demokratik ülkelere yapıldığı, demokratik kurumların fikri mülkiyet haklarını koruyarak DYY üzerinde olumlu etkide bulunduğu, demokratik hükümetlerin ülke güvenilirliği üzerinde etkisi olduğu kabul edilmelidir.

\section{Son Notlar}

1 Gelişmekte olan ülkelerde çevresel kirliliği artıran bu durum teoride "Kirlilik Sığınağı Hipotezi" olarak adlandırılmaktadır.

${ }^{2}$ Daha kapsamlı bir bilgi için bakınız Pedroni (2000). 


\section{Kaynaklar}

Al-Sadig, A.(2009). The effects of corruption on FDI inflows. Cato Journal, 29(2), 267-294.

Arslan, Ü. ve Ökten, N.Z.(2010). The relations between FDI and democracy: Evidence from Turkey. International Research Journal of Finance and Economics, 56,111-123.

Asiedu, E. ve Lien, D.(2011). Democracy, foreign direct investment and natural resources Journal of International Economics, 84, 99-111.

Biglaiser, G. ve DeRouen, K.(2006). Economic reforms and Inflows of foreign direct investment in Latin America. Latin American Research Review, 41(1),51-75.

Brouthers, L.E. Gao, Y. Mcnicol, J.S.(2008). Corruption and market attractiveness influences on different types of FDI. Strategic Management Journal,29, $673-680$.

Busse, M. (2003). Democracy and FDI. Hamburgisches Welt-Wirtschafts-Archiv (HWWA) Hamburg Institute of International Economics, Discussion Paper, 220.

Busse M., ve Hefeker, C.(2007). Political risk, institutions and foreign direct investment. European Journal of Political Economy 23, 397-415.

Caetano, J. ve Calelro, A.(2009). Is there a relationship between transparency in economic and political systems and foreign direct investment flows? The Icfai University Journal of Applied Economics, 8(2),45-58.

Castro, C., ve Nunes, P. (2013). Does corruption Inhibit foreign direct Investment? Politica / Revista de Ciencia Politica, 51(1),61-83

Craigwell, R. Ve Wright A. (2011). Foreign direct investment and corruption in developing economies: Evidence from linear and non-linear panel Granger causality tests. Economics Bulletin, 31(3), 2272-2283.

Cuervo-Cazurra, A.(2006). Who cares about corruptıon?. Journal of International Business Studies, 37, 803-822.

Cuervo-Cazurra, A.(2008). Better the devil you don't know: Types of corruption and FDI in transition economies. Journal of International Management 14,12-27.

Della Porta, D. ve A.Vanucci (1999). Corrupt Exchanges, Actors, Resources and Mechanisms of Political Corruption, New York, NY.

Egger P., ve Winner H.(2005). Evidence on corruption as an incentive for foreign direct investment. European Journal of Political Economy ,21,932- 952.

Egger, P. ve Winner, H.(2006). How corruption influences foreign direct investment: a panel data study. Economic Development and Cultural Change, 54 (2),459-486.

Gani, A. (2007). Governance and foreign direct investment links: evidence from panel data estimations. Applied Economics Letters, 14, 753-756.

Guerin, S.S. ve Manzocchi, S. (2009). Political regime and fdı from advanced to emerging countries. Rev World Econ, $145,75-91$.

Habib, M. ve Zurawicki L. (2001). Country-level investments and the effect of corruption some empirical evidence. International Business Review 10,687-700.

Haksoon , K. (2010). Political stability and foreign direct investment. International Journal of Economics and Finance, 2(3).

Hines, J. (1995). Forbidden payment: Foreign bribery and American business after 1977. National Bureau of Economic Research (NBER) Working Paper 5266.

Im, K.S., Pesaran, M.H. ve Shin, Y. (2003). Testing for unit roots in heterogeneous panels. Journal of Econometrics. 115, 53-74.

Jakobsen, J. ve Soysa, I. (2006). Do foreign Investors punish democracy? theory and empirics, 1984-2001. Kyklos, 59( 3), 383-410. 
Jensen, N.M. (2003). Democratic governance and multinational corporations: political regimes and inflows of foreign direct investment. International Organization, 57(3), 587-616.

Ketkar, K. , Murtuza, A. ve Ketkar, S.L. (2005). Impact of corruption on foreign direct investment and tax revenues. J. of Public Budgeting, Accounting \& Financial Management, 17(3),313-341.

Larrain B., F. ve Tavares, J.(2004). “Does foreign dırect ınvestment decrease corruptıon. Cuadernos De Economıa, 41,217-230.

Levin, A., Lin, C.F. ve Chu, C.S.J. (2002). Unit root tests in panel data: asymptotic and finite-sample properties. Journel of Econometrics. 108, 1-24.

$\mathrm{Li}, \mathrm{Q}$. (2006). Democracy, autocracy, and tax incentives to foreign direct investors: a cross-national analysis. The Journal of Politics, 68 (1),62-74.

Li, Q. ve Resnick, A. (2003). Reversal of fortunes: democratic institutions and foreign direct investment inflows to developing countries. International Organization 57,175-211.

Maddala, G. S., ve Wu, S. (1999). A comparative study of unit root tests with panel data and new simple test. Oxford Bulletin of Economics and statistics, 61(S1), 631-652.

Mathur, A. ve Singh, K. (2013). Foreign direct investment, corruption and democracy. Applied Economics, 45:8, 9911002.

Okafor, C.E. , Ujah, N.U., Elkasssabgi, A.Y. ve Ajalie, W.U. (2011). Democracy and FDI Inflow: Evidence of discordance in Sub-Saharan Africa. International Research Journal of Finance and Economics, 63,140-149.

Oxelheim, L., Randoy, T., ve Stonehill, A. (2001). On the treatment of finance-specific factors within the OLI paradigm. International Business Review, 10(4), 381-398.

Öner, S. (2005). Yolsuzluk Olgusuna Siyaset Bilimi Çerçevesinden Bir Bakış. Sayıştay Dergisi, 57,49-54.

Pedroni, P. (1999). Critical values for cointegration tests in heterogeneous panels with multiple regressors. Oxf. Bull. of Economics and Statistics. 61, 653-670.

Pedroni, P., (2000). Fully modified OLS for heterogeneous cointegrated panels. Advances in Econometrics. 15, 93-130.

Pedroni, P. (2001). Purchasing power parity tests in cointegrated panels. Review of Economics and Statistics. 83, 727731.

Pedroni, P. (2004). Panel cointegration: asymptotic and finite sample properties of pooled time series tests with an application to the PPP hypothesis. Econometric Theory. 20, 597-625.

Primorac, D. ve Smoljic, M. (2011). Impact of corruption on foreign direct investment. Megatrend Review, 8 (2),169190.

Resnick, A.L. (2001). Investors, turbulence and transition: democratic transition and foreign direct investment in nineteen developing countries. International Interactions 27(4),381-398.

Rose-Ackerman, S. (1999). Corruption and Government: Causes, Consequences, and Reform, Cambridge, UK.

Samadi, S. Fathi, S., ve Tahmasebi, S. (2011). Impact of foreign direct investment on financial development present to political corruption in the countries of d-8. Interdisciplinary Journal Of Contemporary Research In Business. $3(5), 445-450$.

Smarzynska, B.K. ve Wei, S.J.(2000). Corruption and composition of foreign direct investment: firm-level evidence. NBER Working Paper No.7969.

Smarzynska, B. K. (2002). The composition of foreign direct investment and protection of intellectual property rights: evidence from transition economies (Vol. 2786). World Bank Publications.

Tosun, M.U., Yurdakul, M.O., ve Varol İyıdoğan P. (2014). The relationship between

corruption and foreign direct investment inflows in turkey: an empirical examination. Transylvanian Review of Administrative Sciences, 42, 247-257. 
Voyer, P.A ve Beamish, P.W.(2004). The effect of corruption on japanese foreign direct investment. Journal of Business Ethics, 50(3),211-224.

Yalçınkaya Koyuncu, J. (2011). Yargı Bağımsızlığı, Mülkiyet Hakkı ve Yolsuzluğun Yabancı Sermaye Girişleri Üzerindeki Etkisi. Dumlupınar Üniversitesi, Sosyal Bilimler Dergisi, 29, 143-148.

Yang, B.(2007). Autocracy, democracy, and FDI Inflows to the developing countries. International Economic Journal, 21(3), 419-439.

Yeşil, S. (2010). Küreselleşme ve İşletmelerin Küreselleşme Süreçleri: Karşılaşılan Fırsatlar ve Tehditler. AiBÜ-iiB Ekonomik ve Sosyal Araştırmalar Dergisi. 